\title{
The Application of Confucius Practice in Management at the Largest Agriculture-Based Conglomerate Group of Companies in Thailand
}

\author{
Athapol Ruangkanjanases, Narumon Posinsomwong, and Chenin Chen
}

\begin{abstract}
This study is a case analysis of the application of Confucius practice in management specifically pertaining to the management practice of Charoen Pokphand Group of Companies. CP Group is one of the leading companies in Thailand, in which its operation started centuries back, and is run by a Chinese family. Confucius has influenced much of the Chinese consciousness such that his teachings and philosophies are practiced from then until now, and have been applied in many different areas including business. CP Group as it is largely a Chinese family business adheres to Confucian philosophy where it maintains hierarchy in its organizational structure, practices leadership by example, and sustains relationship to society through corporate philanthropy.
\end{abstract}

Index Terms-Confucian practice, management, governance, social ethics, paternalistic leadership

\section{INTRODUCTION}

In recent years, Asian economy has spurred up its performance to compete head on with other economies around the world. With positive notes conferred by economic analysts, the upcoming years will be robust for Asian economies with China leading the pack, and Japan's transformation to a new governmental administration is expected to bring growth to its dwindling economy. The anticipated economic cooperation among the Southeast Asian nation in the next two years is also expected to stimulate better economic activities among the region. Thailand has been considered as one of the main players on this economic endeavor thus local Thai companies are gearing up themselves towards this transformation.

One of the companies which may play an important role on this matter will be the Charoen Phokphand Group of Companies, which is considered one of the leading local companies in Thailand. Established in early 1920s by Chinese immigrant brothers, the once small vegetable seed shop has grown to be as what is now known as the $\mathrm{CP}$

Group of Companies which operates various businesses that range from agriculture, telecommunication, petrochemical, automobile, retail, property development among others all over Thailand. Their management system has long been considered as the keystone to their success, and it is on this purpose that this study was conducted.

Manuscript received August 31, 2013; revised October 30, 2013. This work was supported in part by Chulalongkorn Business School, Chulalongkorn University.

The authors are with the Chulalongkorn Business School, Chulalongkorn University, Thailand (e-mail: athapol@cbs.chula.ac.th; hwansung78@hotmail.com; chenin.c@chula.ac.th).
It is believed that traditional Chinese families, wherever they are, always uphold the Confucian concept in leading their lives. Confucius is a philosopher who lived during the early times in China. He had since influenced the consciousness of Chinese people, making them more adept with the brilliance of his teachings and philosophies such that even at this present moment it is evident among their individual practices and could be gleaned through the management system of many of Chinese-ran companies. Confucius's practices always emphasize on how relationship of people in society should be, and how morality should lead people to have better lives.

The CP Group may have been no exception on this matter. Their successes and their long history of business operation in Thailand may also have been guided by the immense work of Confucius. Thus, this study is guided by its three main objectives:

1) To verify the application of Confucian practice in the management of CP Group.

2) To examine how the Confucian practice works in management and brings the group to success.

3) To explore more about the way the Confucian practice can be applied in management.

As there are several books that mentioned about Confucius's teachings and practices as written by his disciples [1]. This study only emphasized on the business application of Confucius's practices as observed and followed by the CP Group.

\section{LITERATURE REVIEW}

\section{A. Confucius's Philosophy}

Confucius or Kong Fu Zi in Chinese (551-479 B.C.) was a thinker, philosopher, teacher and politic figure. He lived in the period of Warring States (403-221 B.C.) in which Chinese states fought each other's. It was a time that politic, society and morality was disordered [2]-[4].

His doctrines can be categorized into three main groups, which are related to governance philosophy, social ethics philosophy, and education [1], [5]. The relationship among these three groups is considered as development roots to bring prosperity in term of mind, body and society to human being. Confucius's philosophy diagram is shown in Fig. 1.

\section{B. Government Philosophy}

In order to make society to be discipline, leader must be a sample of high standard of virtues. The very first thing to do is Zheng Ming, meaning Rectification of Name [6], [7]. If a 
person claims a title for himself in order to be in one of the hierarchical relationship, then he must have the virtue high enough to that particular title in order to be suitable to be in that title. Therefore, Confucius believes that if the ruler's behavior is rectified, the governed people will then follow his virtues [5].

\section{Confucius' Philosophy}

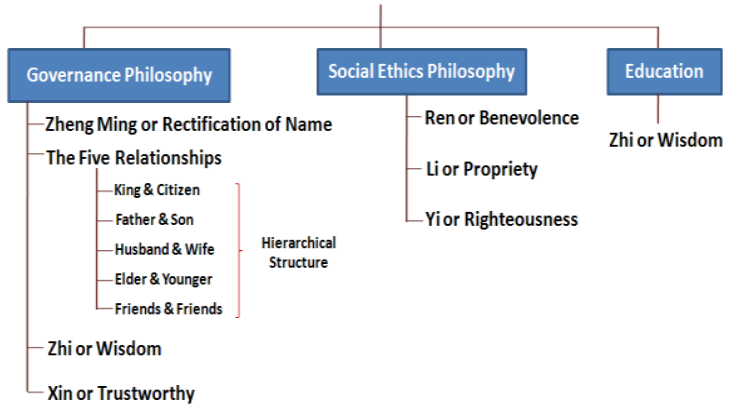

Fig.1. Overall picture of Confucius's philosophy.

People must know their roles and duties of being in their titles [7]. Confucius also introduces the Rectification of Name in term of the Five Relationships (king and citizen, father and son, husband and wife, elder and younger, friend and friend), which support the idea of the rectification [6], [8].

Governance will be smooth when the rulers are moral, justice and have virtues. Confucius believes in these virtues that will be more effective than orders [7]. In order to make it effective, Confucius also recommends 3 factors to support the assumption [8].

First is mutual understanding about moral of both ruler and people. If both sides do not share the same understanding, then acceptance from the people will be hard to happen [8]. Wisdom or Zhi is required in order to achieve the same understanding in this stage.

Second, people must be able to recognize that the rulers have these virtues and have faith in it. Trustworthy or Xin, then, is the most importance in this stage. Being trustworthy means that when the leaders said something they will do according to what they said that they would do [9].

Hierarchical structure- the Five Relationships and the roles and duties of people in society create social organization, which means organizing people. It is to keep people in the harmonious relationships when a lot of people living together. Confucius focuses on family and the responsibility to the whole society. If the society is secured in peace, the individual will be able to perform their functions well. In return, the society will be effective and peaceful [9].

\section{Social Ethics Philosophy}

In social ethics, there are 3 elements involving, which are Ren or Benevolence, Li or Propriety and Yi or Righteousness. These elements must support each other's in order to bring happiness to the society.

Ren or Benevolence - Ren is the heart of Confucius's doctrine. It is the origin of all ethics. Character of Ren is to love people. Confucius believes that the people who are really able to love other people will be capable to do social works.
Li or Propriety - It means doing everything properly. There are 4 dimensions of Li: Rites, Manners, Ethical behaviors and Culture. Confucius thinks that Ren is the basic factor of having $\mathrm{Li}$. $\mathrm{Li}$ is used as a mechanism to control and adapt Ren to be in proper way [8].

Yi or Righteousness - It means doing things that are legitimated to do. It is the right actions that are from benevolent heart as Mencius said that Ren is the heart and Yi is the path. The people who are righteous in their hearts don't think of how correct of their actions would be because their hearts are already in the right place. Righteousness doesn't involve with any benefits to oneself but would do for the good sake of others [10].

\section{Education}

Confucius believes that education will bring Zhi or Wisdom, which will change people's behaviors and encourage them to live morally and harmoniously with other people [11]. There are three learning fundamental from Confucius. First is to learn by experience. It is different from the Western's way focusing on external environments. On the other hand, Confucius focuses on experience from human relationships through the following characters, which are gentle, kindness, respect, simple, ease and honor. A person with these characters will be pleased and welcomed by others. It is knowledge derived from good relationships. Next is to learn about cultures and rites. These cultures and rites such as history, poet, arts and etc. are used as medium to learn how to behave morally [1]. People have to be able to classify cultures and rites whether they are right or wrong. The decision will be based on the fact that the cultures or rites support or lead to harmonized society. Last is to admire, compare with and adapt from others. People must have open heart to integrate with others in order to get the perfect beauty. With experiences, people will be able to pick the right cultures and rites [8].

The real objective of Confucius is to create Junzi or Gentleman [5]. Confucius categorized people into groups by using 2 systems. First is the social position such as prince, minister, father, son, brother and etc. Second is the quality of mind to measure people in term of knowledge, virtues and etc. Under this system, two ends are Junzi and Xiaoren [7].

The most important category is Junzi or Gentleman. Junzi is a person who has studied and sought for moral quality through personal development or self-cultivation. This will bring order and harmony to society and the advancement of the mankind at the end [3]. The growth of the moral quality depends on level of education. Then people with moral quality should have priority to be rewarded with social positions. That's why Confucius's doctrine also requires each social position to possess proper mind. If not, society will be disorder [7]. The opposite of Junzi is Xiaoren or Smallman, which has negative meaning. Xiaoren are those who focus on personal wants and desires but ignore the universal benefits [3], [8]. In general, people will have both Junzi and Xiaoren within oneself. The important thing is how to control Xiaoren [3].

Education helps a lot in self-improvement. People with knowledge will be able to cooperate more effectively rather than the uneducated people [7]. Confucius helps encourage 
people to first improve themselves in order to expand to family level, then to society and the world at the end. This concept of development doesn't only create a caring society but also promote harmony and peace to all mankind [11].

\section{CHARACTERISTICS OF CONFUCIUS ORGANIZATION}

Confucius's practices are influenced by Five Virtues and Five Relationships. Five Virtues give guideline of moral to society, which focuses on harmony. Five Relationships rule over behaviors and roles of the members in organization [12].

\section{A. Characteristics Influenced by Ren}

Paternalistic of Leadership (Junzi Leader) - Leaders who can bring success to organization must have correct virtues, practice kindness and justice equally toward all and have great aspiration, self-control and be role model. Junzi leaders will set themselves as good sample to their subordinates by being ethical and ruling by virtues. Subordinate will trust and respect them by heart. There is no need of strict rules and regulations. Generating trust is the main job for leader. Besides, the leaders will promote others as if promoting themselves [2], [13]. Leader must have ethics because leaders are placed in the top of organization so their behaviors and decision will impact all of their subordinates [14].

Leadership - Real leader will be capable to encourage other surrounding people to work for group goal rather than individual goal or preference and avoid doing something against social values [15]. Since workers have a lifetime commitment to leaders, then the leaders must take care of workers' welfare [16]. They will focus on the welfare of employees as a whole, harmony of the group, teamwork and self-sacrifice. Confucius managers are thrift, loyalty and dedicate to company while they expect employees to work hard for the sake of the whole group [12].

Less rules and Regulations - Organization ruled by virtue is one with less lawsuit and punishment [2]. People have freewill but it will be guided by propriety and righteousness so there is no need to have a lot of rules and punishments. It is good to the management because they can focus on other things, which lead to efficient management [17]. Besides, workers will lack of commitment to organization if they have to strictly follow systems and procedures, which is necessary for innovation and creativity [18], [19]. Rules and regulations should not come from above but the employees, which will lead to acceptance and finally willingness to follow the rules [19].

Promote harmony - Difference is normal in society. Managing these difference and diversity for mutual benefit is called harmony. It is similar to arranging a musical band, which combine different type of instruments, to play their individual roles in order to have beautiful songs [14]. Solutions for conflict are negotiating and compromising to find consensus and harmony [17].

Harmony can be used to make fortune [20]. By having the same dream or goal - strategic intent and/or Corporate Social Responsibility (CSR) can build trust among internal and external stakeholders [19]. Besides, it helps drive the organization in long run as the direction of the company. While short-term is to fulfill the current need of the customer
[14].

Proper welfare, good motivation - Company with good welfare will keep employee happy to work for the company [17]. It is believed that people must be properly motivated. Providing welfare is one kind of motivation [19].

In connection to the dream of the organization, apart from being long-term direction, it is an inspiration of people within the organization as well [14].

\section{B. Characteristics Influenced by $\mathrm{Li}$}

Family based organization - After the end of imperial period in China, most of Chinese migrated to other countries to search for the better living condition. Even though, most of the oversea Chinese doesn't have much education and is not familiar with the Confucius's classics, they are raised in the society that is traditional Confucius so they have the values in their behaviors and actions [20]. The oversea Chinese will group together as an organization or association for example Chinese who come from the same village, same town in China or have the same surname and etc. They would support and help in the form of both labor and money to each other when necessary such as wedding, funeral, festivals. The leader of these groups of people will normally be successful one or have Confucius's righteousness and virtues [11].

Confucius is still in Chinese blood until now as Chinese' style of management is still shown in hierarchy, paternalistic, autocratic control as well as focusing on the importance of family and connections. The Confucian work ethic helps maintains social interconnection. The interconnections, many times are family based [12].

Hierarchical Structure - The organization will be organized in hierarchical structure but with no prejudice or sexist [11]. People have equal right and should be treated with respect and dignity. Junzi leader will use people according to their individual capability. The leaders with high moral standard will promote people by looking at their ability [2].

Mianzi or Face is one kind of showing respect to others. People will normally give respect and honor to others' social status in society or organization [16]. Therefore, rewarding by higher job title is one way to recognize employees and to keep their face. Job title is considered as source of face outside the organization in term of business and social setting. It helps fulfill individual value [21].

\section{Characteristics Influenced by $Y i$}

Legitimate profits and fame - Organization influenced by Confucius will make their fortune and fame through righteousness [19].

\section{Characteristics Influenced by Zhi}

Support Education - Nowadays, executive thinks that company's competitiveness will depend on knowledge and skills of individual in the organization. It can tell the future of the organization [19]. A firm with Confucius practice will focus on knowledge development [14].

Competition - Competition is one kind of relationship with no aim to eliminate the others. It leads to development and knowledge. The competitions that are qualified and necessary to success of an organization must be through virtues such as respect and honesty [14]. 


\section{E. Characteristics Influenced by Xin}

Guanxi (Personal Connection) - Guanxi literally means special personal relationships. It illustrates to be necessary for Chinese business practices, which is based on relationship and connection [22], [23]. The informal network among the oversea Chinese business is considered as one of success factors of Chinese business. Among group, they provide information, contacts and financing. Many Chinese businesses are family-based that even support the harmony of the group [12]. Guanxi also includes connection with mutual obligation, goodwill and personal affection based on family or shared experiences [22]. Network of stakeholders both internal and external can help each other in term of knowledge sharing so relationship is important to lead company to success [14].

Therefore, Guanxi can be divided into four groups, which are family guanxi, non-business friends, business guanxi and government guanxi [23]. One thing that holds this network together is trustworthy, not the ownership or any contracts can do [12].

Work with people with the same virtues - In order to build healthy organization, both leader and subordinate must have reciprocal ethical values and specific values of each side [3]. It could help building trust among each other within the organization. It is believed that trust will appear from shared virtues and share virtue systems in human behaviors, which is unable to control by any system [19].

\section{F. Background of Charoen Pokphand Group}

Charoen Pokphand Group is an empire of various businesses ranging from agricultural products to real estate development. Business groups under CP Group can be categorized into 14 groups of industry namely Agro-Industry \& Food, Automotive, Crop Integration, Feed Ingredients Trading, Finance, Information Technology, International Trading, Pet Food, Plastics, Pharmaceutical, Property Development, Retail, Seeds, Fertilizer, Plant Protection and Telecommunication. The group employs more than 280,000 employees in over 25 countries worldwide.

All of the companies have their own ways to manage business. However, all would receive policy directly from $\mathrm{Mr}$ Dhanin Chearavanont, Chairman and CEO of the Group, and other high rank executives as they are one part of the group. Each company is led by trustworthy management assigned by Mr. Dhanin Chearavanont.

\section{G. Confucius in Management}

Confucius's practice can be applied in business and able to bring success to the organization in term of happiness of the stakeholders and society as well as the shareholders of the organization through ethical derived profits. Fortune and fame must be gained legitimately and with righteousness so the wealth and fame will be worth. The profit will be legitimate without contamination. A real gentleman make profits in Ren, a great man pursue wealth in $Y i$. Trustworthy invites customers from all over the world; righteousness attracts wealth from all directions [3].

It is no doubt that management is under the influence of people so human being is the most important factor in bringing organization to success [15], [19]. Confucius's philosophy focuses on human being, which starts on one self. So management and Confucius are closely related. Philosophy is the general guidance for management while management is an experiment of philosophy to test if the philosophy is practicable or not [15].

It has been proved that systems and processes are required only to support but no longer drive the organization. However, the most important factor for the successful and sustainable organization is based on the relationships between individuals who work together harmoniously [19].

\section{RESEARCH METHODOLOGY}

The leading enterprise, "Charoen Pokphand Group" has been chosen to be the research subject. Literature review and public record were being used for better understanding of its background and ways of management related to Confucianism. Observation and interview were conducted with $\mathrm{CP}$ current employees to learn their behavior and attitudes toward the inherited Confucius practices. The interviews were conducted with employees working in various positions and functions in the different companies under C.P. Group. Questions were divided in four parts as follows;

Part 1: demographic information

Part 2: attitude toward working performance and working environment

Part 3: attitude toward organization

Part 4: attitude toward leadership in the organization

The interviews were conducted from August to November 2011. All the interviewees were picked randomly. Among 20 interviewees, half of them were in management level and the other half were in staff level. Their comments were purely their own opinions toward the company in which they are working for. All information was analyzed to find out if the company applied Confucius' practices in their working environment.

\section{ANALYSIS AND FINDINGS}

The results are arranged into 3 main categories, which are about leader, structure of companies and organizational management and policy. These categories cover all aspects of the whole organization, which are the combination of the success. The Confucius characteristics of CP Group are shown in Fig. 2.

\section{Confucius characteristics of C.P. Group}

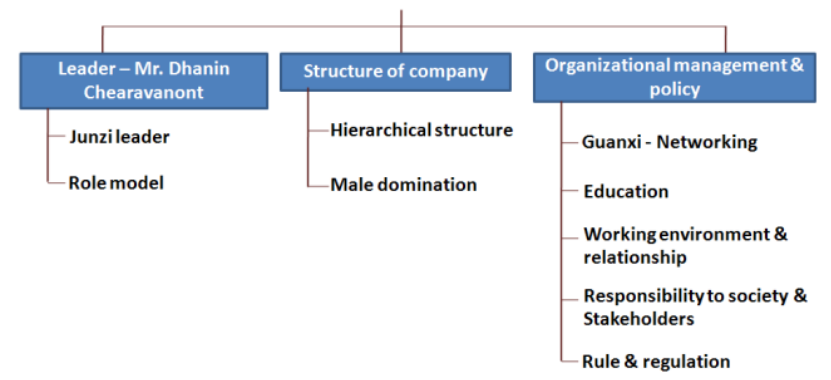

Fig. 2. Confucius characteristics of CP Group. 


\section{A. Leader - Mr. Dhanin Chearavanont}

According to the aspects of being a Junzi, the researcher found that Mr. Dhanin Chearavanont possesses qualifications matching with Junzi's aspects of all virtues.

First of all, the most important qualification is Zhi or wisdom. Even though he graduated from commercial college, he has been cultivated himself through work experience and from others. Moreover, he doesn't just learn new technology from other countries and apply that technology in Thailand. But he adapts the technology to fit with Thailand environment. This shows that he learns, thinks and then practices. Besides, he always learns from the experience of others, not only from the expert in the matters but also from his staffs. Not only for himself, has he also supported learning and training of all staff as one of the main policy applied to all companies.

He always gives his subordinates a chance to work even though they may do some mistakes. If they admit the mistakes, he will forgive and let them continue working. But if they don't accept the mistake, he will not assign any work for the person again. This style of working has been a main model for the working style in C.P. Group. From the interview, it shows that executives and supervisors follow this style. They all say the same that their bosses will always give staff a chance. Moreover, he treats people equally and promotes subordinates who are competence to work rather than promote his sons or relatives if they don't have capacity to work. As illustrated in his policy, that he will not let his sons to work in the businesses that are already success. He will let them prove themselves by building a company and make it successes. For example, Mr. Supachai Chearavanont brings success to True Corporation on his own. These aspects illustrate that he has Ren.

$\mathrm{Yi}$ and $\mathrm{Li}$ can be illustrated through his business philosophy to do business ethically, honestly and fairness. "Be honest to customer. If customer is in hardship, we are also in hardship. If customer is wealthy, we are also wealthy." is always in his mind.

Xin can be shown when he assigns people to do jobs such as he trusts Mr. Korsak Chairasmisak to recover 7-Eleven and CP All PCL. and Mr. Thanakorn Seriburi to take care of the company in China during the economic reform in 1979. Mr. Dhanin Chearavanont has the ability to see his subordinates' capacity and trust in them. On the contrary, he is trustworthy to all of his brothers to take lead of the whole group in 1989. All three brothers trust Mr. Dhanin that he will be able to lead the group to success.

From the interview, all interviewees support that $\mathrm{Mr}$. Dhanin Chearavanont is a smart leader because he could see other capabilities and utilizes them at the right time and place. Some of them mentioned that he is a very smart man and always give junior employee a chance. Indirectly, they believe that all the main policies are given from him and trust that he will lead to the right direction.

\section{B. Structure of Companies in CP Group}

Hierarchical Structure - As influenced by $\mathrm{Li}$, the organization applying Confucius will be structured in hierarchy. From the interview, all confirmed that the companies they are working for have a very high hierarchical structure. Many layers of authority are in place. Even though each will have their own authority to make decision at some level, any decision effecting on the process or policy of the company must be made by the higher ranks.

Each level will be titled differently. Some levels are differentiated by the education background. For example, Staff level is the most junior level who possesses Bachelor Degree, while Officer is also junior level but possesses a Master Degree.

In order to be promoted, many factors will be considered such as experience, competence and most importantly performance. However, they all think that it is not creating a fighting environment because the companies apply 360 degree evaluation. They rather feel that they would like to compete with themselves in order to improve their works than compete with others. This structure somehow helps them to know their career paths clearly and motivate them to work hard in order to get promoted.

However, they all agree to some extent that sometimes this structure may not be good for the companies that need to move fast in the business world such as retail business. One interviewee said that in the business world today, it is no longer true that a big fish will eat smaller fish but rather faster fish will eat the slower fish.

Some interviewees think that the hierarchy structure can help reducing aggressiveness of western management system that allow employee to comment directly to the boss. At the same time it increases the carefulness in doing business because of experience of the high rank positions that may see problem lying ahead, which the younger may not see. These people are the one who make decision.

Male Domination - As influenced by the five relationships, one policy of the group is that they will not allow daughter or daughter in law of very senior executives to involve in any business. For example, two daughters of Mr. Dhanin Chearavanont don't work in any companies under the group.

Within C.P. Group, all the top executives are male. If looking further down into structure of company, for example CP All PCL, there are about 45 executive positions responsible for different fields. It shows that three female are in the executive positions, which is equal to approximately 6 percent. One female is in Assistant Vice President Level and two are in Vice President Level. From the interview, four out of five bosses are males.

However, it illustrates that C.P. Group used to adopt the practice in the sense of five relationships. But Ren has been more focused and the company adapt it to fit the real world that female has been more educated and are competence to work. Therefore, chances have been given to female who are competent to work in the high level of management.

\section{Organizational Management and Policy}

Guanxi (Personal Connection) - This is one of the strategies for success of C.P. Group. It is clearly shown that Xin has been applied as base of this strategy. Mr. Dhanin Chearavanont has always built relationship with the experts within the industries he wishes to enter. This is illustrating that C.P. Group has followed the ways of making networking with his business partners.

CP Group also has maintained good relationship with the 
government of China. This network with Chinese government is really hard to establish because they don't really trust the group whether the company will just come to exploit in the land and then leave. The company must earn trust from the government.

Education - From the interview, CP Group emphasizes on the education for staffs. It all starts in the very beginning of their career path. The orientation will last approximately a week. It will be about getting to know the company, work related procedures and applications and especially ethics for society.

Superiors and all executives also emphasize to all staffs to think about society when doing something. Each company in $\mathrm{CP}$ Group has different policies but one core value is the company must have ethics toward all stakeholders.

Training is what the company always emphasizes. In general, each company under CP Group has its own training center, arrange the course themselves but invite lecturers from industries or academic institutions.

Even further study for a graduate degree is supported. One of the interviewees is doing her Master's Degree. She started it after working with the company for about 2-3 months. Her boss and the company always support her.

Besides, some part of the company is arranged as Knowledge Center. It is a small library for all staffs, for example, the Knowledge Center of C.P. All PCL located on the $6^{\text {th }}$ Floor, Sriboonruang Building.

Ethical business - According to the company's philosophy, whatever CP Group would do, they must consider that it will benefit the country, people and company. Doing business in ethical ways will lead the company to success. This philosophy is influenced by Ren, Yi and Li.

Society - Expansion of business is also one way to help society in terms of creating jobs. Each company under C.P. Group has its individual Corporate Social Responsibility projects with long term commitment. For example, the six groups of C.P. Foods PCL.'s CSR projects including technology transfer, environment and energy saving, health and consumer care, public welfare, sport and other relations projects.

In relation to the flooding situation in Thailand in 2011, one of the interviewee from CPF and works in Marketing mentioned that actually CPF contributed a lot more than it had been in the news. She just wonders why CPF doesn't promote this. For the others, they all said the same that C.P. Group did a very good job and made a lot of contribution to the help community.

Supplier and customers - According to the contract farming policy, C.P. Group also supports their suppliers by taking all the risk from market side. It helps making sure that the suppliers will be able to sell their products.

According to the interview with a Deputy General Manager of CP All PCL., he insists by refers to a survey conducted by AC Nielsen that among retails business, 7-Eleven is in a good rank of suppliers' satisfaction survey rated by all suppliers in term of not taking advantages from the suppliers. However, he admitted that there might be a conflict of interests but the company is trying its best to compromise.

From the interview, customers' happiness is the first thing that CP All PCL. emphasizes when doing business and when training their staffs. The interviewees also mentioned that the most popular word in any meetings is customer's happiness. It can show through the motto of the company, which is "Wish for the smile of customers by happy employees".

Employee - Happiness of the employee is also one of the main concerns of the group as much as the customers. In order to have a lot of talents within the company, the company must make employee secure and happy.

All of the interviewees mentioned the same that at $\mathrm{CP}$ Group, there is no lay off policy. Even in the last economic crisis, every employee gets the same level of salary and benefits. One of the philosophy said by Mr. Korsak Chairasmisak is "We don't just take care our people, but also their families." Another example is that one department was suspended. Company tried to find the other task or project for these people to work on.

During flooding crisis in 2011, some employees had affected by the flood. The company established an assistant center for staffs. Every employee could call this center for emergency help. The company also prepared shelter for the staffs and family members. Staffs could also find accommodation themselves and reimburse a certain amount of allowance later.

In term of general benefits, CP Group tries to take good care and values their employee. For example, if someone working on one particular floor catches cold, the company will clean the whole floor so that nobody will be infected.

Overall, all the interviewees are currently happy about the employment condition that CP Group offers. They all feel secure in their work.

Working environment and relationship within company This is the matter of Ren and Xin. Mr. Dhanin Chearavanont is a role model and has influenced on working style of many executives of CP Group. As mentioned that he will tell only what he wants and let his staffs work on it. This is also the way that supervisors or executives at C.P. Group have followed. All of the interviewees said that they will find the ways out for the assigned tasks. However, when assigned tasks, they believe that the supervisors know who is capable of doing the tasks. They trust that their staffs can complete the work for them.

CP Group promotes employees to work in team. The interviewees agree that the way of working at CP Group is through meetings. They often have meetings. The meeting will help staffs from various but relevant departments to think together, to learn from others and to combine the best ideas to the work. This is the process of creating harmony, which is the one of the most important objectives of Confucius.

All staffs are encouraged to give comments to the works. This is applied to all level. All interviewees said that the higher executives consider all comments of the staffs. If any ideas or comments are good, then they will adopt it without any prejudice.

The good relationship with in company is always emphasized as mentioned by Mr. Korsak Chairasmisak. "Happiness doesn't come from good remuneration. Even though we give very high salary, we talk harshly to them. They can tolerate but not very long then they leave. 
Happiness comes from many sources. Remuneration must be proper but the most important thing is good relationship. We must work on it as our standard and apply to all level."

In overall relationship in the company, all of the interviewees confirmed that they have good relationships with all parties such as colleagues, bosses and subordinates. They work together like a family who cares about each other. Some mentioned that even though they get a new job offering, they are reluctant to leave the company because they are afraid that they will not be able to find this working environment in the new place. Bosses are always welcome to give advice and support. Colleagues are really helpful. Subordinates are dedicated and work hard. Some say that this will be their last workplace. The reason to leave the company is to have their own business. All confirmed that they are not going to leave the company very soon.

Rules and regulations - The matter is supposed to be influence by Ren but after interview, the researchers found that there were mixtures of Ren, Li and Yi. Minimum rules and regulations are applied. The company is flexible to the lower level staffs to some extent. If a staff breaks some rules, the punishment is not so serious and will not effect to the remuneration or promotion.

All interviewees said the same that C.P. Group has some rules to follow such as in-out time for the staff in lower level. The company doesn't take it seriously if the staff doesn't come in so late than the normal working hours. It can be flexible. This rule will not apply to the higher ranking employees. There will be no in-out time recording. However, defrauding is one thing that is prohibited. Even one baht, the company will not compromise and consider it as unacceptable behavior.

\section{CONCLUSION}

The CP Group has adopted the main teachings of Confucius in their business management. This is especially so, since the company put more attention to human resources and has tried their best to retain good, competent people. Even though that the company applies hierarchical organizational structure, the comments and opinions of the lower rank employees are still valued.

The organization has good image towards its stakeholders. This brings trust to its employees, and its customers. It is also found that there are three main factors that keep people in this organization - authority, money and the hope to advance in their career. These all are being provided by the company although it is important to note this may not satisfy all of its employees as they may have other goals in their lives.

However, it is notable that CP Group emphasizes a lot in learning and education. They encourage their people to initiate advancement in their respective careers by taking further studies. But aside from these technical skills, the company also implants ethics among them. The company encourages their people to think of the society, not only about themselves. This makes CP Group having a good image towards its stakeholders.

CP Group has always applied networking strategy into their business. They always have a professional partner working side by side with them as clearly shown in each of their business ventures.

Confucius could be seen around the CP Group. The probable reason why Confucian practices are applicable in Thailand is the similarity of Chinese and Thai culture. Both Chinese and Thai cultures follow through the concept of hierarchy and seniority. In modern business world this seniority process may be imperative to guide young generation of workers to be more skillful in their works.

In conclusion, this study verified that Confucian practices are present, and widely used in the management system of the CP Group. It is also found out that the practices and teachings of Confucius bring about success to the company up to this day. But more importantly, this study attested that Confucian practices, philosophies and teachings could be applied to management practice.

\section{REFERENCES}

[1] A. Sudthayakorn, "An analysis of concept of the relationships in Confucius's teachings," Master's Thesis, Department of Philosophy, Faculty of Arts, Chiang Mai University, Chiang Mai, Thailand 2008.

[2] J. A. Fernandez, "The Gentleman's code of Confucius: Leadership by values," Organizational Dynamics, vol. 33, no. 1, pp. 21-31, February 2004.

[3] S. H. Lee, "Confucian leadership and ethics - New Insights from old wisdoms," Unpublished, Taiwan, 2011.

[4] R. Devitt, "Confucianism: understanding and applying the analects of Confucius," Education about Asia, vol. 12, no. 1, pp. 1-3, spring 2007.

[5] J. Riegel. (Fall 2002). Confucius. The Stanford Encyclopedia of Philosophy. [Online]. Available: http://plato.stanford.edu/entries/confucius/.

[6] X. M. Feng. (2009). What i've learned studying the find Chinese tradition xin (Trustworthiness). [Online]. Available: http://www.tsoidug.org/papers_xin.php.

[7] W. B. Zhang, Confucianism and Modernization, Industrialization and Democratization of the Confucian Regions, Hampshire: Macmillan Press Ltd., 1999.

[8] S. Suwanna, Lun Yu Analects of Confucius 2008, Bangkok: Chulalongkorn University Press, 2008, pp. 90.

[9] C. Wee, "Xin, trust, and Confucius' ethics," Philosophy East and West, vol. 61, no. 3, pp. 516-533, July 2011.

[10] P. C. Lai and P. Lee. (March 2002). Traditions of giving in Confucianism. Alliance Magazine. [Online]. Available: http://www.alliancemagazine.org/en/content/traditions-giving-confuci anism.

[11] C. H. Tan, "Confucianism and nation building in Singapore," International Journal of Social Economics, vol. 16, no. 8, pp. 5-16, 2007.

[12] C. A. Rarick, "Confucius on management: Understanding Chinese cultural values and management practices," Journal of International Management Studies, vol. 2, no. 2, pp. 1-8, August 2007.

[13] J. S. Hill, "Confucianism and the art of Chinese management," Journal of Asia Business Studies, vol. 1, no. 1, pp. 1-9, 2006.

[14] E. J. Romar, "Strategic intent, Confucian harmony and firm success," Acta Polytechnica Hungarica, vol. 6, no. 3, pp. 57-67, 2009.

[15] C. H. Lin and Y. K. Chi, "Chinese Management Philosophy - Study on Confucius Thought," Journal of American Academy of Business, Cambridge," vol. 11, no. 1, pp. 191-196, March 2007.

[16] J. Wang et al., "Confucian values and the implications for international HRD," Human Resource Development International, vol. 8, no. 3, pp. 311-326, September 2005.

[17] J. Yan and Associates. (1998). Individual Wills First-the Real Success Behind the Asian Tigers. [Online]. Available: http://www.jyanet.com/cap/0613fe0.htm.

[18] H. Opdebeeck and A. Habisch, "Compassion: Chinese and western perspectives on practical wisdom in management," Journal of Management Development, vol. 30, no. 7/8, pp. 778-788, 2011.

[19] E. Weymes, "A challenge to traditional management theory," Foresight, vol. 6, no. 6, pp. 338-348, 2004.

[20] T. B. Li and G. O. Moreira. (2009). The Influence of Confucianism and Buddhism on Chinese Business - The Case of Aveiro, Portugal. [Online].

http://www.immi.se/intercultural/nr19/tianbo.htm. 
[21] J. Ryan and P. Rose, "Human resource management with Chinese characteristics: An Exploratory study of confucian principles, organisational structure and retention," New Zealand Journal of Human Resources Management, vol. 10, no. 2, pp. 68-82, winter 2010

[22] M. J. Chen. (2001). Inside Chinese Business: A Guide for Managers Worldwide. [Online].

Available: http://www.quickmba.com/mgmt/intl/china/.

[23] X. Y. Zhao, "Guanxi (Special Personal Connections) and business success in China," Chinese Public Affairs Quarterly, vol. 1, no. 3, pp. 211-223, 2005

Athapol Ruangkanjanases is a faculty member at Department of Commerce, Chulalongkorn Business School, Chulalonglorn University. He received his Ph.D. from Illinois Institute of Technology, USA. Before joining Chulalongkorn University, he taught at the School of Management Marist College, New York, USA.

Narumon Bosinsomwong was the graduate of Master of Management Program in International Business, Chulalaongkorn Business School, Chulalongkorn University. She is working as the administration officer of Royal Danish Embassy in Thailand and also be a freelance translator.

Chenin Chen is an adjunct associate professor at Chulalongkorn Business School, Chulalonglorn University. He received his D.B.A. from United States International University, California, USA. He is the managing director of Rayong Wire Industries Public Company Limited. He is also sitting as board director of Capital Engineering Network Public Company Limited and Ua Withya Public Company Limited; both are listed companies in Stock Exchange Market Thailand. 